\title{
Create and Validate Hybrid Ventilation Components in Simulation using Grasshopper and Python in Rhinoceros
}

\author{
Hoda Barzegar Ganji ${ }^{1}$, Dennis Michael Utzinger ${ }^{1}$, David E Bradley ${ }^{2}$ \\ ${ }^{1}$ University of Wisconsin Milwaukee, Milwaukee, WI, USA \\ ${ }^{2}$ Thermal Energy System Specialists, LLC, Madison, WI, USA
}

\begin{abstract}
Pulling components from grasshopper for means of performance analysis is getting more common than using a standalone simulation model. While this trend results in a revolution in Performative Based Design (PBD), there are a few deficiencies including lack of validation of the components and lack of inclusivity of simulation tools in hybrid systems.

This paper looks at validating components in ventilation simulation modelling through measured data from Schlitz Audubon Nature Center (SANC) in Bayside, Wisconsin. Moreover, it investigates integration of self-written Earth Tube components into the model. The main takeaway of this paper is the process of validation and creation of python-based components in grasshopper.
\end{abstract}

\section{Introduction}

Perhaps the first attempts to define ventilation were made in the late nineteenth century. It was not as easy to define "ventilation" as it had been to define "heating" or "cooling". It was not easy to measure ventilation either. Maybe because it was still more of a qualitative idea expressing "freshness" rather than a quantitative measurable item. Gradually, the two main offenders in poor air quality were exposed: Carbon Dioxide, and excessive moisture (Banham, 1984).

Over years, more pollutants were revealed. The American Society of Heating, Refrigerating and Air-Conditioning Engineers (ASHRAE) defines ventilation as: "the process of supplying air to or removing air from a space for the purpose of controlling air contaminant levels, humidity, or temperature within the space." ASHRAE considers a wide range of elements as contaminants including Carbon dioxide, Carbon monoxide, Formaldehyde, Lead, Nitrogen dioxide, Ozone, Particles of various sizes, Radon, Sulfur dioxide, Odors, etc.

Following a period of trying to use purely mechanical means to improve air quality, today both natural and mechanical ventilation systems are used when designing a new building. While higher occupant satisfaction, lower Sick Building Syndrome, and lower utility costs are a few merits of natural ventilation systems, reliability and unpredictability are still the most significant challenge these systems face. (Dutton, Et al. 2013; Seppanen and Fisk, 2002; Rupp, Vasquez and Lamberts, 2015; Brager and Arens, 2015; Candido, Et al. 2010; Leyten and Kurvers, 2006;Axley, 2001; Melton, 2014).
Considering the limitations and advantages of both natural ventilation and mechanical air-conditioning systems, there seems to be an alternative solution to take advantage of the benefits of both approaches. This solution is known as hybrid ventilation. The hybrid strategy employs natural ventilation in the mild months and mechanical ventilation in warmer and colder periods (da Graca and Linden, 2016). Chen Et al. consider the hybrid strategy as coupling natural ventilation with mechanical ventilation (Chen, Augenbroe, Song, 2018). Heiselberg mentions that the main difference between a conventional ventilation system and a hybrid one is the control system that switches between the two modes resulting in mitigating energy consumption (Heiselberg, 2002; Brager, Borgeson, Lee, 2007).

A couple of world famous buildings with a hybrid ventilation system are the Deutsche Messe AG Hannover Administration Building located in Hanover, Germany (Herzog, 2000) and Manitoba Hydro Place located in Winnipeg, Manitoba in Canada (Lauster and Olsen, 2008). Both designs benefit from control strategies. In the Hanover Building, a mechanical device closes the air inlet as soon as the occupant opens the window (Herzog, 2000). In Manitoba Hydro Place, a comprehensive energy management plan has been incorporated into the daily operations under supervision of an energy management engineer and a building controls specialist.

The Schlitz Audubon Nature Center (SANC) in Bayside, WI and the Aldo Leopold Foundation (ALF) in Baraboo, WI are two nature centers both of which benefit from hybrid ventilation systems. The ALF building also employs an earth tube system as part of its mechanical ventilation strategy. In this system, the ground works as a heat sink in summer and heat source in winter (Ascione, Bellia, Minichiello, 2011; Peretti, Zarrella, De Carli, Zecchin, 2013).

The Earth Tube system in the ALF was designed to preheat, precool and pre-dehumidify the air. Simulation revealed that it is more efficient than the enthalpy heat recovery system (Bradley and Utzinger, 2009). Based on data measurement from ALF, an algorithm to analyze the thermal performance of an Earth Tube system has been proposed (Ganji, Utzinger, Renken, 2018).

In this paper, a natural ventilation model of the auditorium at SANC is created using off-the-shelf components for TMY climate data and natural ventilation tools from Ladybug (Sadeghipour Roudsari and Park 2013). The 
paper includes the results of attaching a hypothetical Earth Tube heat exchanger to room, adding mechanical ventilation and looking to keep thermal comfort in the desired range.

\section{Methods}

\section{Experiment}

The Schlitz Audubon Nature Center (SANC) building is located at Bayside, WI, next to Lake Michigan. The hill on the east side connects the building to the water edge. SANC is about $30 \mathrm{~m}$ above the lake level.

The auditorium of SANC, which is shown by the red color in Figure 1, is located at the North side of the building. It is designed to benefit from natural ventilation through six operable windows in the breathing zone, three at the east and three at the west side, promoting cross ventilation. It also has operable windows on both the east and west sides of a clerestory space above the breathing zone. These, however, were not considered in the experiments.
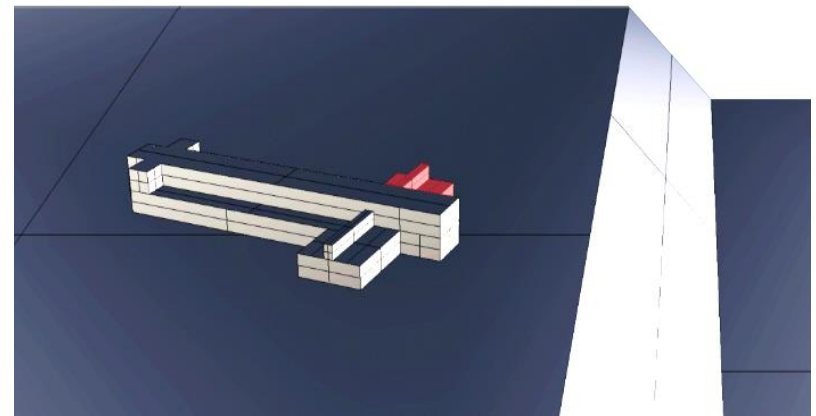

Figure 1: SANC Building

On October $16^{\text {th }}, 2005$, David Bradley and Michael Utzinger performed Carbon dioxide $\left(\mathrm{CO}_{2}\right)$ measurement experiments on the auditorium. They measured $\mathrm{CO}_{2}$ level in the auditorium as well as the outdoor $\mathrm{CO}_{2}$ level, temperature, relative humidity, wind speed and wind direction. A gas cylinder was then used to add $\mathrm{CO}_{2}$ to the space at a rate of $0.566 \mathrm{~m}^{3} / \mathrm{hr}$. In Experiment 1, only a single leeward and a single windward window were open. In Experiment 2, all six auditorium windows were open (Bradley and Utzinger, 2006). They further did a test having the clerestory windows open, but the ventilation rate did not significantly change. Hence, the stack effect has been negligible and cross ventilation is considered as the main type of airflow.

Based on Appendix C of ASHRAE Standard 62.1-2013, the required outdoor airflow rate per person is related to the difference between the $\mathrm{CO}_{2}$ level in the space and in the outdoor air (ASHRAE 62.1, 2013). Knowing the amount of initial and final $\mathrm{CO}_{2}$ level in a space as well as the outdoor $\mathrm{CO}_{2}$ level during a certain amount of time, we can calculate the actual natural ventilation rate. The actual ventilation rate could be compared to the ASHRAE required amount of ventilation to see whether the natural ventilation is sufficient in the auditorium of the SANC building or not. Whenever the ventilation target is not hit, mechanical ventilation would be required. This could lead us to the basics of the control system of a hybrid ventilation approach in terms of switching between the natural and mechanical modes.

\section{Simulation of Natural Ventilation}

Natural ventilation simulation happens in two steps. Step 1 studies the SANC building and the auditorium room in the larger context. Step 2 focuses only on the auditorium.

In step 1, a Computational Fluid Dynamics (CFD) model is developed in Autodesk Simulation CFD. This model helps us comprehend the air flow around the auditorium. Air velocity, pressure coefficients and effectiveness of openings can be estimated based on the CFD results.

The inputs of the CFD model are based on the 2005 experimental data. The wind speed is $1 \mathrm{~m} / \mathrm{s}$. The wind direction is 66 degrees or East North-East direction; that is, the wind is coming from the lake, heading up the hill and almost perpendicular to the east windows. The CFD simulation includes the lake breeze effect (Figure 2).

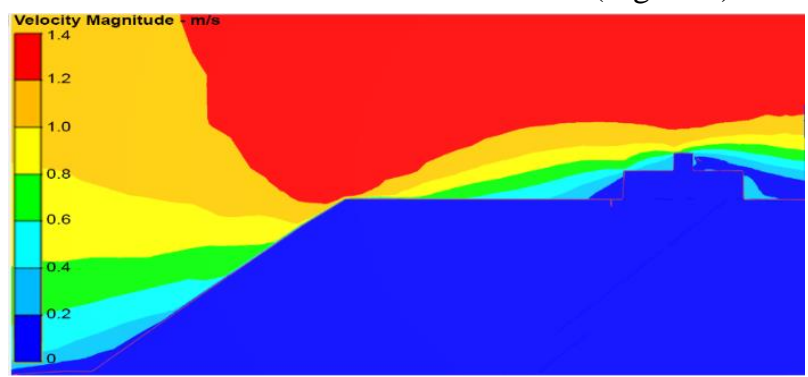

Figure 2: SANC Building CFD Model, Section

In step 2 , the natural ventilation in the auditorium is simulated with both two and six windows open by means of Ladybug tools in grasshopper. The Ladybug components use the EnergyPlus engine, which is aligned with the ASHRAE Fundamentals (EnergyPlus 8.9.0 Engineering Reference, 2018; ASHRAE Fundamentals, 2013). Equation 1 is the basis of cross ventilation calculations.

$$
Q=C_{v} A U
$$

$\mathrm{Q}=$ Airflow rate, $\mathrm{m}^{3} / \mathrm{s}$

$\mathrm{C}_{\mathrm{v}}=$ Effectiveness of openings

$\mathrm{A}=$ Free area of inlet opening, $\mathrm{m}^{2}$

$\mathrm{U}=$ Wind speed, $\mathrm{m} / \mathrm{s}$

Based on this simulation, the air flow rate caused by the natural ventilation will be obtained. Next, this number will be compared to the ventilation rate required in the auditorium.

Minimum ventilation rates in breathing zones are listed in the ASHRAE Standard 62.1-2013 for various occupancy categories (ASHRAE 62.1, 2013). Equation 2 determines the minimum airflow value as a function of number of occupants and the floor area.

$$
V_{b z}=R_{p} \times P_{z}+R_{a} \times A_{z}
$$

$\mathrm{V}_{\mathrm{bz}}=$ Outdoor airflow of the breathing zone, $\mathrm{L} / \mathrm{s}$

$\mathrm{R}_{\mathrm{p}}=$ Outdoor airflow rate per person, $\mathrm{L} / \mathrm{s}$-person

$\mathrm{P}_{\mathrm{z}}=$ Zone population

$\mathrm{R}_{\mathrm{a}}=$ Outdoor airflow rate per unit area, $\mathrm{L} / \mathrm{s}-\mathrm{m}^{2}$

$A_{z}=$ Zone floor area, $\mathrm{m}^{2}$

The natural ventilation simulation is further validated by means of the experiment data. 


\section{Simulation of Mechanical Ventilation}

Should two conditions be satisfied, a control element of a hybrid system activates the natural ventilation mode. First, the natural ventilation system should be able to provide the minimum airflow rate. Second, the outdoor weather temperature and relative humidity should be in the thermal comfort range. The first condition depends on climatic specifications such as air temperature, wind speed and direction, as well as the design parameters such as the area of the openings and their arrangement. The second condition only relies on the outdoor weather situation.

In case the air velocity is not sufficient for natural ventilation, or the outdoor air is too hot, humid or cold, mechanical ventilation takes over. Hence, to study the mechanical ventilation mode, thermal comfort and the psychrometric chart will be investigated first. While there are different tools for studying thermal comfort, we are going to employ Ladybug components to remain consistent and carry out all the simulations in Rhinoceros and grasshopper. Mechanical ventilation is simulated using Honeybee components in grasshopper (Roudsari, Mackey, Yezioro, Harriman, Chopson, Ahuja, 2014).

A simple fan coil unit with available hot water is modeled to meet the heating requirements from November $1^{\text {st }}$ through April $30^{\text {th }}$. The days during which the room could be operated in natural ventilation mode with either one or three windows open on either side are determined by analyzing ambient temperature, relative humidity and comfort conditions from May through October.

\section{Simulation of a Hypothetical Earth Tube System}

This section considers a scenario in which a theoretical Earth Tube (ET) system is added to the auditorium to assist with the mechanical ventilation. The system will not only provide the airflow requirement, but also (ideally) save energy due to its pre-heating and pre-cooling features. The same schedules are used in Earth Tube simulation as well as in prior simulations. While the Earth Tube system (which includes a fan) provides the required airflow rate, we will observe the amount of energy that could have been saved due to the passive pre-heating and pre-cooling. The simulation has been carried out using Python-based components in grasshopper written by the first author. The model is developed based on monitoring the Earth Tube system of the Aldo Leopold Foundation (ALF) building (Ganji, Utzinger, Renken, 2018).

Many papers on Earth Tube neglect the conduction of the soil and consider only the convective heat transfer between the air and the soil as shown in Equation 3 (Mongkon, Thepa, Namprakai, Pratinthong, 2013; Mongkon et al. 2014).

$$
\dot{q}_{\text {Conv }}=m_{a} C_{P}\left(T_{o}-T_{i}\right)
$$

$\dot{\mathrm{q}}_{\text {Conv }}=$ Convective heat transfer rate, $\mathrm{kW}$

$\mathrm{m}_{\mathrm{a}}=$ Mass flow rate of the air inside the tubes, $\mathrm{kg} / \mathrm{s}$

$\mathrm{C}_{\mathrm{P}}=$ Specific heat of air, $\mathrm{kJ} / \mathrm{kg}-\mathrm{K}$

$\mathrm{T}_{\mathrm{o}}=$ Outlet temperature of the air inside the tubes, $\mathrm{K}$

$\mathrm{T}_{\mathrm{i}}=$ Inlet temperature of the air inside the tubes, $\mathrm{K}$
Our model considers both the convection and the conduction of the soil (Equation 4).

$$
\dot{q}_{\text {Conv }}+\dot{q}_{\text {Cond }}=m_{a} C_{P}\left(T_{o}-T_{i}\right)
$$

$\dot{\mathrm{q}}_{\text {Cond }}=$ Conductive heat transfer rate, $\mathrm{kW}$

The Python model interfaces in the form of a few grasshopper components each of which is responsible for a specific task.

The first component creates the tubes geometry based on the user inputs including the base point, number of tubes, tube radius, tube length, depth, etc. (Figure 3).

This is the only component which has geometrical visual effects in the Rhinoceros environment. By changing any input, the geometry will update in the Rhino environment instantaneously. Other parameters required as inputs of the other components are obtained as outputs of this component.

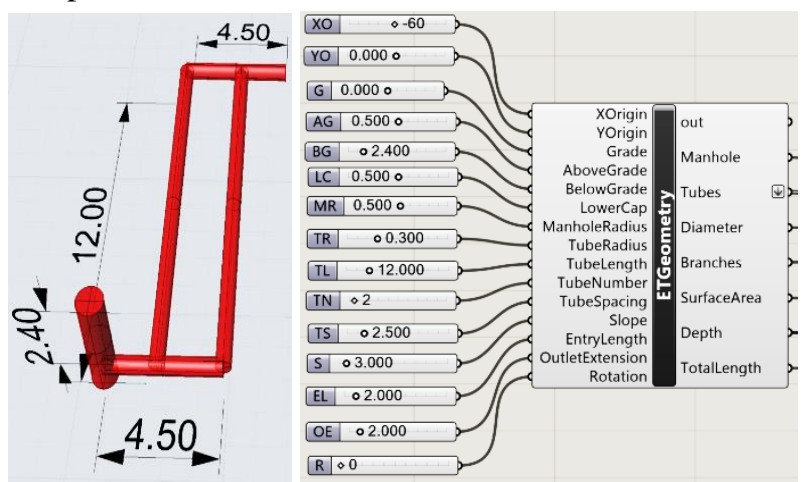

Figure 3: Grasshopper Component, ET Geometry

Next the ET component gets the air temperature, relative humidity and pressure from the Ladybug EPW component and calculates air density, viscosity, Prandtl number, humidity ratio, specific heat, and conductivity (Figure 4).

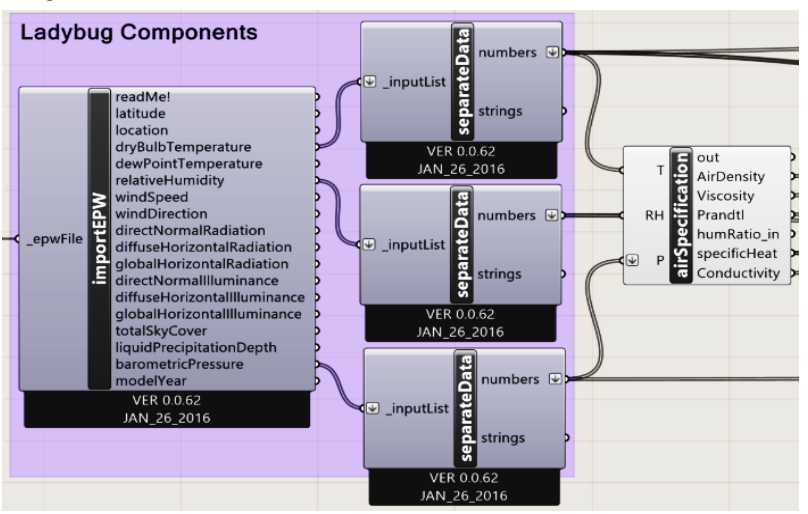

Figure 4: Grasshopper Component, Air Specification

The third component receives the geometric information from the first component, air state from the second one, and fan volume flow rate as a direct input. Then, it calculates all coefficients we need including conduction shape factor, heating and cooling convective heat coefficient, as well as mass flow rate (Figure 5).

The next component is responsible for calculation of the undisturbed soil temperature as a function of depth, type of soil and type of the year based on the Kusuda equation (Kusuda and Achenbach, 1965). 


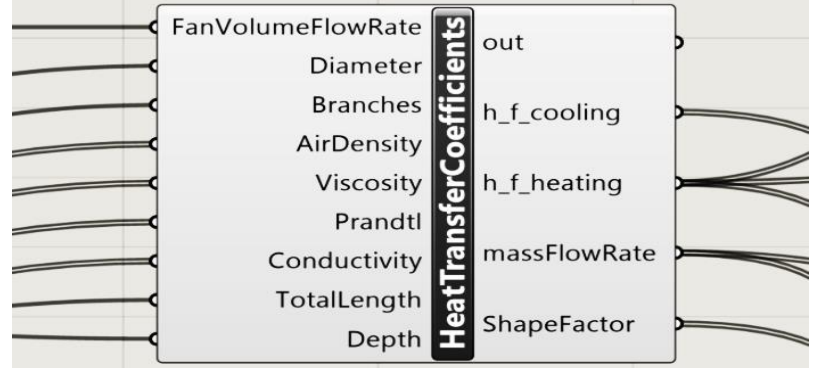

Figure 5: Grasshopper Component, Coefficients

Figure 6 represents the outcome of this component, the soil temperature $3 \mathrm{~m}$ below the surface ground. The annual average of the soil temperature is $7.7^{\circ} \mathrm{C}$.

The earth tube system disturbs the soil thermally: during the winter, the earth tubes takes energy from the soil to warm up the outdoor air and in summer it warms the soil in the vicinity of the tubes up. The model is simplified by assuming the soil temperature to be the same as the undisturbed one.

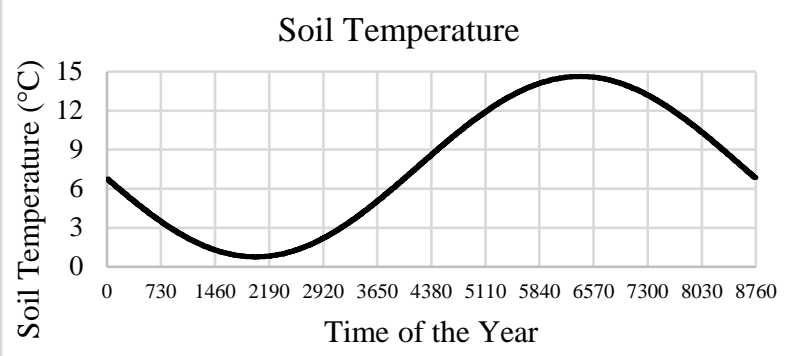

Figure 6: Soil Temperature

Having the soil temperature, the only unknown in Equation 4 would be the temperature of the air at the outlet of the tubes. A numerical method has been developed to calculate the outlet temperature. Then, the outlet temperature is plugged back into either side of the Equation 4 to obtain the amount of saved energy.

\section{Results and Discussion}

\section{Validation of Natural Ventilation Simulation}

This section focuses on the validation of the natural ventilation component of the Ladybug tools. First, we calculate the airflow rate in the auditorium in two scenarios matching with Experiment 1 and 2 using Equation 1. Then, this number is used as the basis to verify both the equation and the simulation results.

In Experiment 1, the auditorium was brought from its natural $\mathrm{CO}_{2}$ concentration up to $1000 \mathrm{ppm}$. Then, two out of six windows (one leeward and one windward) were opened. The $\mathrm{CO}_{2}$ level was seen to drop to $800 \mathrm{ppm}$ in 15 minutes. The outdoor $\mathrm{CO}_{2}$ level was approximately constant at $384 \mathrm{ppm}$ (Bradley and Utzinger, 2006). The room volume is $714 \mathrm{~m}^{3}$. Accordingly, the natural ventilation rate is $258 \mathrm{~L} / \mathrm{s}$ assuming that the zone was well mixed and that the measured $\mathrm{CO}_{2}$ concentration was representative of the entire air volume. While this approach provides a convenient way to estimate the airflow rate, it is somehow limited since we are assuming homogeneous indoor air properties by considering only one air node representative of the indoor conditions.
However, this simplified method is also available in airflow modeling software such as CONTAM (Dols, 2002). It is worth noting that the height of SANC auditorium is only one third of its width; that is, it is not very tall as compared to its width. In the case of this room, one node seems a reasonable assumption.

In Experiment 2, the same room was brought to 1250 ppm. All six windows (three leeward and three windward) were then opened. The $\mathrm{CO}_{2}$ level dropped to $670 \mathrm{ppm}$. During Experiment 2, the outdoor $\mathrm{CO}_{2}$ level was 385 ppm (Bradley and Utzinger, 2006). The ventilation rate is then $532 \mathrm{~L} / \mathrm{s}$. Due to the wind direction, during the experiment and the building orientation, the wind hit the auditorium at an almost perpendicular angle during the experiments (Figure 7).

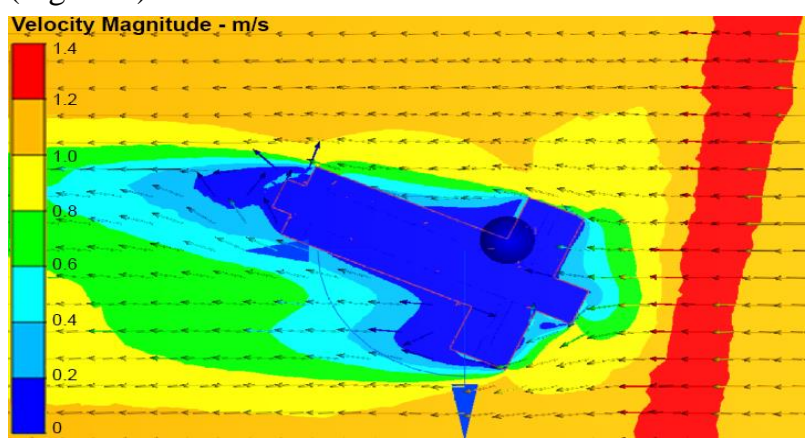

Figure 7: SANC Building CFD Model, Plan

A CFD analysis was used to compute wind pressure coefficients for the facades. After importing the geometry from Rhino, adding a volume of air, assigning boundary conditions - including the wind speed on the windward side, zero pressure on the leeward side, and slip-symmetry on the other sides - and creating a dense set of mesh ,we solved the CFD model in a steady state mode. The solution converged after 393 iterations. The pressure coefficients were obtained as part of the result quantities.

Because of the wind direction, we could insert the lower range of opening effectiveness for perpendicular winds, which is 0.5 , into Equation $1 . C_{v}$ is typically between 0.5 to 0.6 for perpendicular winds (ASHRAE Fundamentals, 2013).

Based on Equation 1, the airflow rate for the conditions in Experiments 1 and 2 would be $186 \mathrm{~L} / \mathrm{s}$ and $557 \mathrm{~L} / \mathrm{s}$ respectively. These numbers are comparable with the experiment.

The measured data was limited to the duration of the experiment. For the validation of the simulation, we directly used the measured data through replacing the numbers in the Typical Meteorological Year (TMY) file by the measured numbers for the day of the experiment.

We were interested to extend the simulation to the whole year. For this means, we compared the TMY data with the measured quantities. While the temperature and relative humidity were close to the experiment, the wind speed reported in the data file was higher than the number measured at the site. It might be because of the fact that the meteorological station is located outside of the dense urban area; accordingly, wind speed would be much higher. By comparing the TMY wind speed and the 
measured wind speed, we came up with the factor to be multiplied by the TMY wind speed so that the wind speed would be adjusted to the site conditions.

The simulation shows $236 \mathrm{~L} / \mathrm{s}$ and $575 \mathrm{~L} / \mathrm{s}$ of airflow for Experiments 1 and 2 respectively. The simulation numbers are comparable to the experiments, within $8 \%$ of uncertainty, which validates the Honeybee natural ventilation component.

\section{Thermal Comfort and Psychrometric Chart}

In this section, temperature, relative humidity and comfort conditions are studied to determine which days the auditorium could be operated in natural ventilation mode with either one or three windows open on either side.

There are different tools and apps available to study thermal comfort. Ladybug has a set of components to draw psychrometric charts. To keep the whole study in one software, thermal comfort is studied through the Ladybug tools.

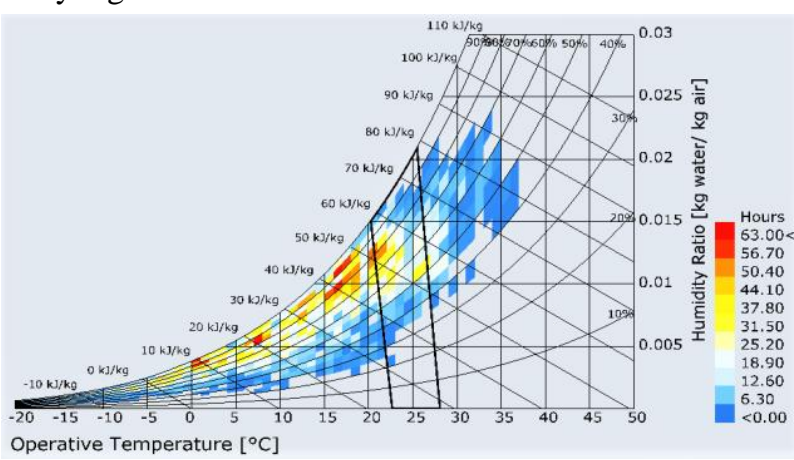

Figure 8: Psychrometric Chart

According to the psychrometric chart, the outdoor air conditions are conductive to natural ventilation mode only $10 \%$ of the year. The number of hours that the temperature is below $22^{\circ} \mathrm{C}$ is dominant, whereas the number of hours when the temperature exceeds $28{ }^{\circ} \mathrm{C}$ is minimal (Figure 8 ). As a result, the role of natural ventilation would be limited to the swing and cooling season.

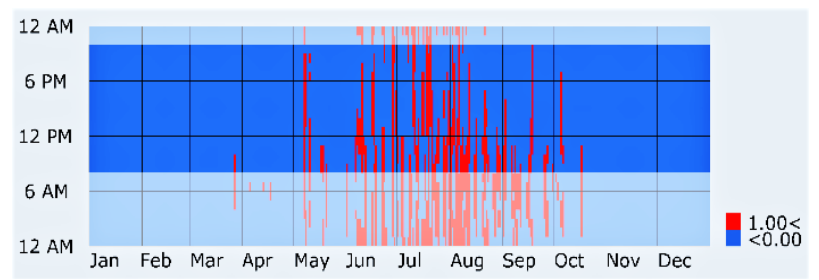

Figure 9: Total Comfort Chart

Figure 9 illustrates the comfortable hours more vividly. The time of the year with no occupancy is covered with a transparent white layer. The red and blue colors depict comfortable and uncomfortable hours respectively. There are only a few comfortable hours during November through April.

\section{Hybrid Ventilation in Heating Season}

Based on Figure 9, the outdoor conditions are not typically comfortable during the heating season. Natural ventilation would only increase levels of discomfort. Hence, ventilation will be in mechanical mode during November through April.

\section{Hybrid Ventilation in Cooling Season}

For May through October, we should consider two issues: thermal comfort and adequacy of natural airflow. The natural ventilation mode will be activated if and only if both conditions are satisfied. In this section, we will first study the thermal comfort in the cooling season. Then, we investigate if the natural airflow is sufficient in the comfortable hours.

Figure 9 displays the comfort hours based on the outdoor weather data. However, the real comfort hours inside the auditorium might change considering the material, construction, occupancy, internal gain schedules, lighting schedule and so on. Figure 10 displays the simulation of the room with respect to the mentioned items without additional mechanical ventilation.

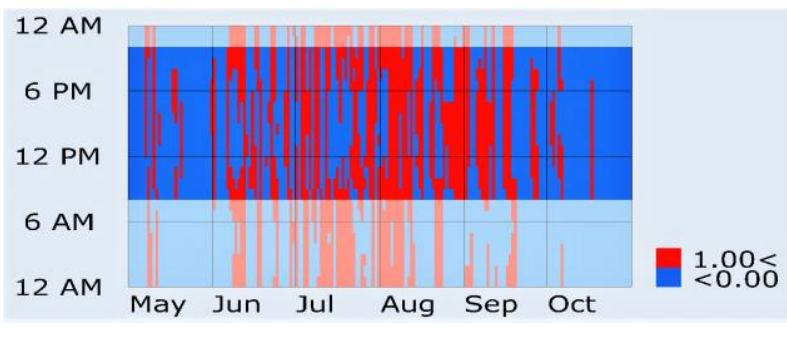

Figure 10: Comfort Chart, Cooling Season

During the cooling season, 5, 11, 14, 18, 14 and 3 days are thermally comfortable in May, June, July, August, September and October respectively (Figure 11). In these 65 days, there are only two days in which the required natural ventilation rate does not meet the target with two windows being open, May $12^{\text {th }}$ and September $8^{\text {th }}$. Unlike September $8^{\text {th }}$, on May $12^{\text {th }}$, opening six windows would not help.

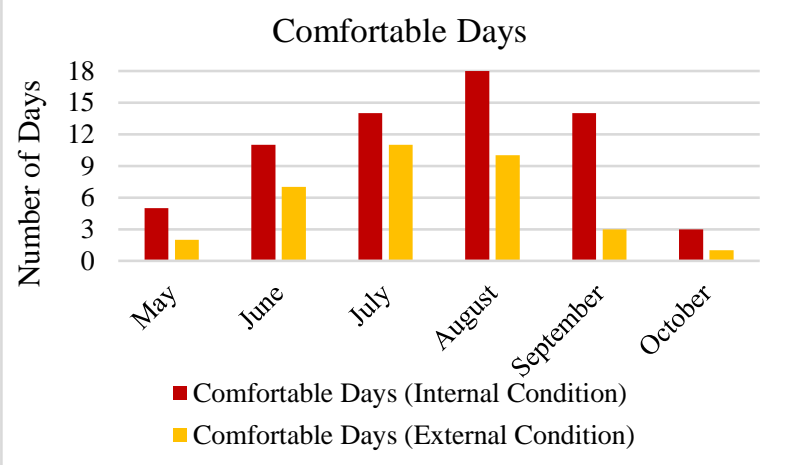

Figure 11: Number of Comfortable Days, Cooling Season

To sum up, there are 64 days during the May through October period when natural ventilation mode could be activated. For the remaining 120 days, we are going to need mechanical cooling. Otherwise, the natural ventilation would only increase the possibility of discomfort.

\section{Program, Occupancy and Schedule}

The auditorium is a multi-use space. Occupancy schedule follows seven days per week, 9 am to 5 pm Sunday through Thursday and 9 am to $10 \mathrm{pm}$ Friday and Saturday. There are typically 15 people in the room from 9 am to 5 
pm every day and 80 people from $5 \mathrm{pm}$ to $10 \mathrm{pm}$ Friday and Saturday (typical wedding reception days in summer).

Based on Equation 4, the minimum airflow, $V_{b z}$, for the auditorium is $107 \mathrm{~L} / \mathrm{s}$ when 15 people are in the room and $354 \mathrm{~L} / \mathrm{s}$ when there are 80 people in the room. The rates have been considered in the schedule.

The Ladybug and Honeybee tools have some predefined schedules as well as some components that allow you write your own schedules. The schedule is written using grasshopper components for the whole year containing 8760 items.

The occupancy schedule is a multiplication of two schedules. One considers the occupancy hours (which do not change from summer to winter). The second one considers the use of natural ventilation mode during 64 days of summer. The days in which natural ventilation is possible are given a value of zero, and the rest are assigned a value of 1 . When this schedule is combined with the first, it causes the fan to turn off whenever the outdoor conditions are suitable to leave the windows open.

\section{Heating Loads Simulation}

In this section, we look into the mechanical system used to provide the heating requirement in winter. Then, the possibility of saving some energy by means of an alternative hybrid solution will be studied.

A fan coil unit is modeled using Honeybee components from November $1^{\text {st }}$ through April $30^{\text {th }}$. The construction, occupancy and schedule are already assigned.

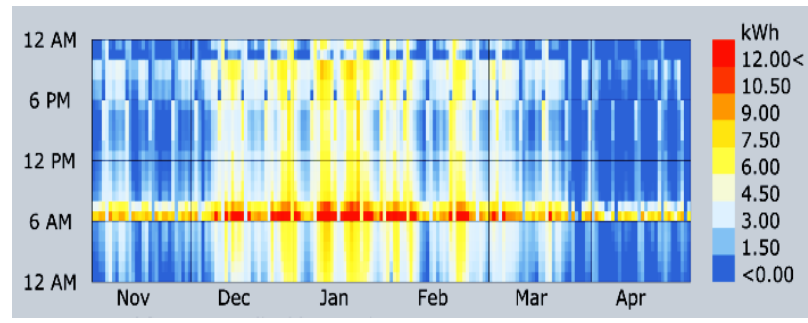

Figure 12: Hourly Heating Load ( $k W h$ )

Figure 12 illustrates the hourly heating load for the auditorium. The peak hourly heating load is about $12 \mathrm{~kW}$. The annual total heating load of fan coil is $10,170 \mathrm{kWh}$. This includes both heating and fan loads.

\section{Cooling Loads Simulation}

As the cooling season in Bayside, WI, is relatively short, the total cooling load is $2280 \mathrm{kWh}$ during May through October. Using a fan coil unit, this number considers both the cooling and the fan loads. The peak hourly cooling load hardly ever exceeds $9 \mathrm{~kW}$ (Figure 13).

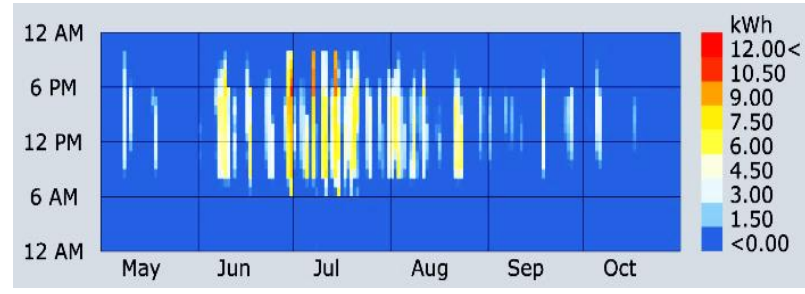

Figure 13: Hourly Cooling Load ( $k W h)$

\section{Earth Tube Geometry Optimization}

There are a few items which tremendously affect Earth Tube performance including the depth at which the tubes are buried, the length, number and diameter of the tubes, the fan volume flow rate, the soil conditions, the outdoor weather, etc.

Some of these items are out of our control such as the weather data. Some of them, we can control to some extent. For instance, excavation up to $3 \mathrm{~m}$ should be convenient. While the deeper the soil, the higher the potential energy saving would be, similar papers consider $2 \mathrm{~m}$ to $3 \mathrm{~m}$ as an optimum (Peretti, Zarrella, De Carli, Zecchin, 2013).

Some of them might have common sense estimation. As a case in point, we might consider the diameter of the tubes to be $0.6 \mathrm{~m}$ so that a person could crawl into them if need be. Volume flow rate depends on the estimated number of occupants as already discussed.

So far, some of our variables allocate some fixed numbers to themselves. Let us consider Bayside, WI, weather condition, a depth of $3 \mathrm{~m}$ for the soil and a diameter of 0.6 $m$ for the tubes. Now, the influential parameters would only be the number of the tubes and the length of them. These two items give us the total length of the tubes.

Theoretically, there should be a limitation to the amount of saved energy in an Earth Tube system. This limitation is determined by the outlet temperature which in turn follows the soil temperature. In fact, the temperature of the outlet of the tubes can never be lower than the soil temperature in summer and warmer in winter. The heat flows from warmer object to the colder one until they come to a temperature equilibrium. That is, the direction of the heat is from soil to air in winter and from air to soil in summer. Ultimately, the outlet temperature would ideally be the same as the soil temperature although in practice this cannot happen unless the earth tube is infinitely long, and the soil is highly conductive. In this case, the soil temperature determines the total length of the tubes which in our case is $125 \mathrm{~m}$. There is no use of considering a longer set of tubes since the outlet temperature stays the same - which equals the soil temperature in each moment.

Table 1 studies the total heating and cooling energy saved due to the Earth Tube system in a year as a function of the number of the tubes and the length of them.

Table 1: Total Saved Energy, ET ( $\mathrm{kWh})$

\begin{tabular}{|l|l|l|l|l|l|l|}
\hline & $\mathbf{1 0} \mathbf{~ m}$ & $\mathbf{1 2} \mathbf{~ m}$ & $\mathbf{1 4} \mathbf{~ m}$ & $\mathbf{1 6} \mathbf{~ m}$ & $\mathbf{1 8} \mathbf{~ m}$ & $\mathbf{2 0} \mathbf{~ m}$ \\
\hline \# 3 & 5370 & 5820 & 6175 & 6432 & 6653 & 6846 \\
\hline \# 4 & 6038 & 6363 & 6640 & 6879 & 7074 & 7212 \\
\hline \# 5 & 6425 & 6743 & 7000 & 7185 & 7292 & 7358 \\
\hline
\end{tabular}

Figure 14 displays the Total amount of saved energy as a function of total tubes length. As one can observe, the points represent a non-linear relationship between the total tubes' length and the annual saved energy. Instead they show diminishing returns as the tube length is extended. 
As the total tubes' length approaches $125 \mathrm{~m}$, the curve tends to converge. In this case, total tubes length greater than $125 \mathrm{~m}$ does not result in higher level of saved energy with the made assumptions.

\section{Total Saved Energy in Earth Tube}

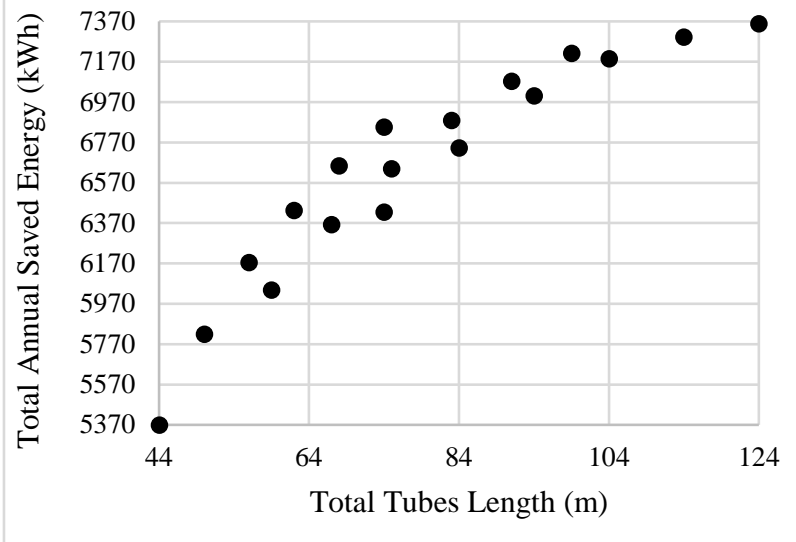

Figure 14: Total Saved Energy, ET ( $k W h)$

To provide $125 \mathrm{~m}$ of tube, a configuration of 5 branches are considered to fit properly on the footprint. Figure 15 displays the tubes arrangement regarding to the auditorium.

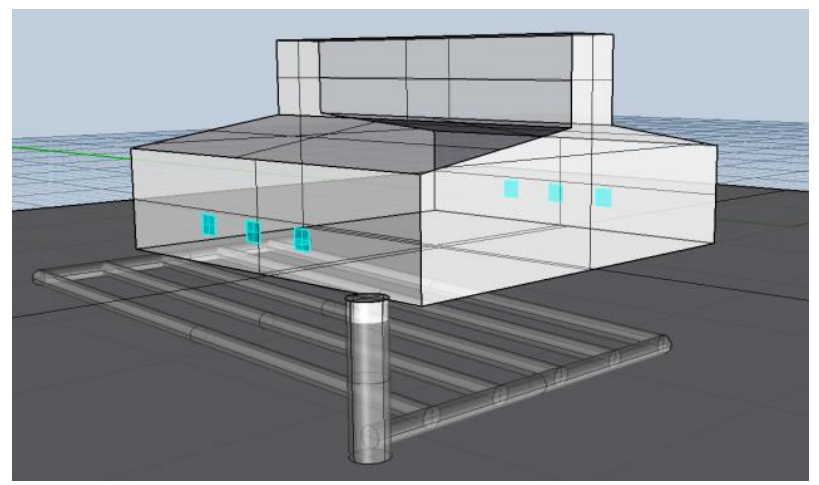

Figure 15: Final Arrangement

\section{Earth Tube Energy Saving}

By attaching the outcome of the Earth Tube components to the Ladybug 3D Chart component, we can present the heating and cooling loads in the same way as the EnergyPlus results are presented (Figure 16 and 17).

Had we added this Earth tube system to the auditorium, the total amount of heating energy that could have been saved is $4535 \mathrm{kWh}$ in a year. This is about $46 \%$ of the total fan and heating load of the fan coil during winter. We would still need energy to run the Earth Tube fan, but the heating load would have significantly decreased.

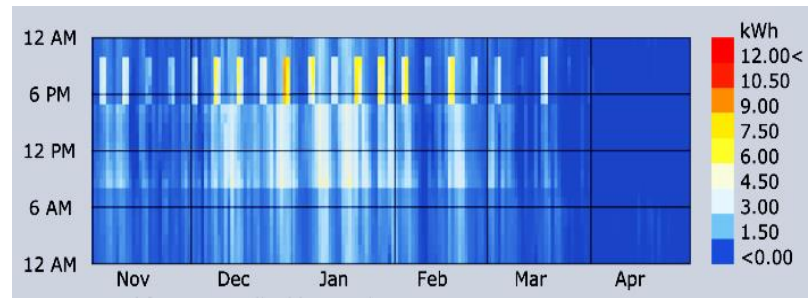

Figure 16: Hourly Saved Heating Energy, ET (kWh)
Figure 17 displays the hourly cooling energy which could have been saved thanks to the Earth Tube system. Hypothetically, all the required cooling energy for the SANC auditorium could have been provided during the cooling season by means of an Earth Tube system. We would still need to run the Earth Tube fan during the 120 days of the cooling season.

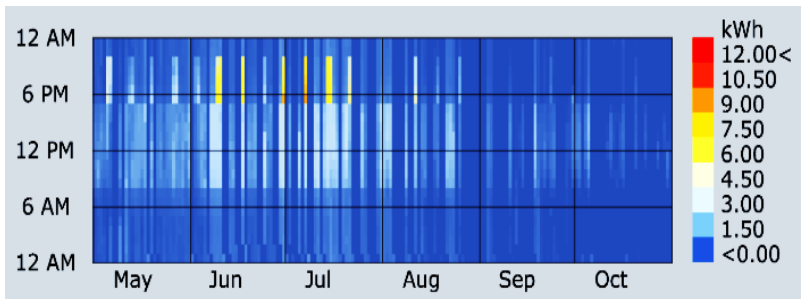

Figure 17: Hourly Saved Cooling Energy, ET (kWh)

Overall, 55\% of annual energy (6848 kWh) would have been saved by adding an earth tube system. Figures 16 and 17 are comparable to Figures 12 and 13 respectively.

\section{Conclusion}

Passive ventilation approaches seem to provide greater occupant control, healthier air, and save more energy. On the other hand, mechanical systems tend to maintain pressure more steadily, perform more reliably, and provide thermal comfort more precisely (Axley, 2001). Hybrid systems benefit from both natural and mechanical ventilation.

While there are some components to simulate natural and mechanical ventilation systems separately, there are not adequate tools to simulate both as part of a hybrid system. This paper explains the control strategy to switch between the two modes and puts forward a model which integrates not only the natural and mechanical components, but the control system as well.

The idea behind this research is to keep all the simulation pieces in the same place that the 3D modeling happens, the Rhinoceros. One can design, visualize, evaluate, and even optimize the system in only one platform needless to switch between numerous software.

The simulation provides a visualization of the system as well so potential conflicts between the building and the ventilation system components would show up early in the design and can be solved more conveniently.

The paper does not suffice to only presenting the model but validates it as well through measured data from Schlitz Audubon Nature Center (SANC) in Bayside, Wisconsin.

The methodology used in this paper in terms of creation of python-based simulation components in the design software (Rhino), validation and finally optimization of the system is a process which can be extended to other aspects of Performative Based Design (PBD).

\section{Acknowledgement}

The authors would like to thank Kyle Talbott and Dr. Kevin Renken, Associate Professors at University of Wisconsin Milwaukee for their help and support regarding the Earth Tube script and simulation. 


\section{Nomenclature}

\begin{tabular}{|l|l|}
\hline $\mathrm{A}$ & Free area of inlet opening, $\mathrm{m}^{2}$ \\
\hline $\mathrm{A}_{\mathrm{z}}$ & Zone floor area, $\mathrm{m}^{2}$ \\
\hline $\mathrm{ALF}$ & Aldo Leopold Foundation \\
\hline $\mathrm{C}_{\mathrm{P}}$ & Specific heat of air, $\mathrm{kJ} / \mathrm{kg}-\mathrm{K}$ \\
\hline $\mathrm{C}_{\mathrm{v}}$ & Effectiveness of openings \\
\hline $\mathrm{CO}_{2}$ & Carbon dioxide \\
\hline $\mathrm{CFD}$ & Computational Fluid Dynamics \\
\hline $\mathrm{ET}$ & Earth Tube \\
\hline $\mathrm{m}_{\mathrm{a}}$ & Mass flow rate of the air inside the tubes, $\mathrm{kg} / \mathrm{s}$ \\
\hline $\mathrm{P}_{\mathrm{z}}$ & Zone population \\
\hline$\dot{\mathrm{q}}_{\mathrm{Cond}}$ & Conductive heat transfer rate, $\mathrm{kW}$ \\
\hline$\dot{\mathrm{q}}_{\mathrm{Conv}}$ & Convective heat transfer rate, $\mathrm{kW}$ \\
\hline $\mathrm{Q}$ & Airflow rate, $\mathrm{m}^{3} / \mathrm{s}$ \\
\hline $\mathrm{R}_{\mathrm{a}}$ & Outdoor airflow rate per unit area, $\mathrm{L} / \mathrm{s}-\mathrm{m}^{2}$ \\
\hline $\mathrm{R}_{\mathrm{p}}$ & Outdoor airflow rate per person, $\mathrm{L} / \mathrm{s}-$ person \\
\hline $\mathrm{SANC}$ & Schlitz Audubon Nature Center \\
\hline $\mathrm{T}_{\mathrm{i}}$ & Inlet temperature of the air inside the tubes, $\mathrm{K}$ \\
\hline $\mathrm{T}_{\mathrm{o}}$ & Outlet temperature of the air inside the tubes, $\mathrm{K}$ \\
\hline $\mathrm{U}$ & Wind speed, $\mathrm{m} / \mathrm{s}$ \\
\hline $\mathrm{V}_{\mathrm{bz}}$ & Outdoor airflow of the breathing zone, $\mathrm{L} / \mathrm{s}$ \\
\hline
\end{tabular}

\section{References}

Ascione, F., Bellia, L., \& Minichiello, F. (2011). Earth-to-air heat exchangers for Italian climates. Renewable Energy, 36(8), 2177-2188.

ASHRAE Standards Committee. (2013). ANSI/ASHRAE/IES Standard 62.1-2013: Ventilation for Acceptable Indoor Air Quality. Atlanta, GA: American Society of Heating, Refrigerating and Air-Conditioning Engineers.

American Society of Heating, R. a. A. E. (2013). 2013 Ashrae handbook: Fundamentals (Inch-pound ed.). Atlanta, Ga.: Ashrae.

Axley, J. W. (2001). Application of Natural Ventilation for U.S. Commercial Buildings.

Banham, R. (1984). The architecture of the well-tempered environment. Chicago (USA).

Bradley, D. E., \& Utzinger, D. M. (2006). Natural ventilation measurements and simulation at two Milwaukee nature centers. Proceedings of SimBuild, 2(1).

Bradley, D. E., \& Utzinger, D. M. (2009). Post Occupancy Calibration and Reassessment of Design Phase Energy Modeling. $11^{\text {th }}$ IBPSA Conference, Glasgow, Scotland.

Brager, G., \& Arens, E. (2015, March). Creating high performance buildings: Lower energy, better comfort. In AIP Conference Proceedings (Vol. 1652, No. 1, pp. 58-69). AIP.

Brager, G., Borgeson, S., \& Lee, Y. (2007). Summary report: control strategies for mixed-mode buildings.

Cândido, C., De Dear, R. J., Lamberts, R., \& Bittencourt, L. (2010). Air movement acceptability limits and thermal comfort in Brazil's hot humid climate zone. Building and Environment, 45(1), 222-229.
Chen, J., Augenbroe, G., \& Song, X. (2018). Evaluating the potential of hybrid ventilation for small to medium sized office buildings with different intelligent controls and uncertainties in US climates. Energy and Buildings, 158, 1648-1661.

Da Graça, G. C., \& Linden, P. (2016). Ten questions about natural ventilation of non-domestic buildings. Building and Environment, 107, 263-273.

Dols, W.S. and G.N. Walton. CONTAMW 2.0 User Manual. National Institute of Standards and Technology. 2002.

Dutton, S. M., Chan, W. R., Mendell, M. J., Barrios, M., Parthasarathy, S., Sidheswaran, M., ... \& Fisk, W. J. (2013). Evaluation of the indoor air quality procedure for use in retail buildings.

EnergyPlus. (2018). Engineering Reference, Version 8.9. 0 Documentation.

Ganji, H. B., Utzinger, D. M., \& Renken, K. J. (2018). An Analysis on the thermal performance of a Horizontal Earth Tue System.

Heiselberg, P. K. (2002). Principles of hybrid ventilation.

Herzog, T. (2000). Sustainable Height: Deutsche Messe AG Hannover. Administration Building: Prestel Pub.

Kusuda, T., \& Achenbach, P. R. (1965). Earth Temperature and Thermal Diffusivity at Selected Stations in the United States.

Lauster, M., \& Olsen, E. (2008). High Comfort- Low Impact.

Leyten, J. L., \& Kurvers, S. R. (2006). Robustness of buildings and HVAC systems as a hypothetical construct explaining differences in building related health and comfort symptoms and complaint rates. Energy and Buildings, 38(6), 701-707.

Melton, P. (2014). Natural Ventilation: The Nine Biggest Obstacles and How Project Teams Are Beating Them. Environmental Building News, 23(8).

Mongkon, S., Thepa, S., Namprakai, P., \& Pratinthong, N. (2013). Cooling performance and condensation evaluation of horizontal earth tube system for the tropical greenhouse. Energy and Buildings, 66, pp. 104-111.

Mongkon, S., Thepa, S., Namprakai, P., \& Pratinthong, N. (2014). Cooling performance assessment of horizontal earth tube system and effect on planting in tropical greenhouse. Energy Conversion and Management, 78, 225-236.

Peretti, C., Zarrella, A., De Carli, M., \& Zecchin, R. (2013). The design and environmental evaluation of earth-to-air heat exchangers (EAHE). A literature review. Renewable and Sustainable Energy Reviews, 28, 107-116.

Roudsari, M. S., Mackey, C., Yezioro, A., Harriman, C. S., Chopson, P., \& Ahuja, S. (2014). Honeybee.

Rupp, R. F., Vásquez, N. G., \& Lamberts, R. (2015). A review of human thermal comfort in the built environment. Energy and Buildings, 105, 178-205.

Sadeghipour Roudsari, M., \& Park, M. (2013). Ladybug: a parametric environment plugin for grasshopper to help designers create an environmentally-conscious design. Paper presented at the IBPSA Conference, Lyon, France.

Seppanen, O., \& Fisk, W. J. (2002). Relationship of SBS-symptoms and ventilation system type in office buildings. 